\title{
Effects of cigarette smoke and chronic hypoxia on airways remodeling and resistance. Clinical significance.
}

\begin{abstract}
Elena Olea ${ }^{a}$, Elisabet Ferrer ${ }^{\star}$, Jesus Prieto-Lloret ${ }^{a}$, Carmen Gonzalez-Martin ${ }^{a}$, Victoria Vega-Agapito ${ }^{a}$, Elvira Gonzalez-Obeso ${ }^{a}$, Teresa Agapito $^{a}$, Victor Peinado ${ }^{b}$, Ana Obeso $^{\mathrm{a}}$, Joan Albert Barbera ${ }^{\mathrm{b}}$ and Constancio Gonzalez ${ }^{\mathrm{a}}$

${ }^{a}$ Department of Biochemistry and Molecular Biology and Physiology, and IBGM Universidad de Valladolid and CSIC Valladolid, Spain ${ }^{*, b}$ Department of Pulmonary Medicine, Hospital Clínic-Institut d'Investigacions Biomèdiques August Pi i Sunyer (IDIBAPS); Universitat de Barcelona; Spain, ${ }^{a, b}$ Ciber de Enfermedades Respiratorias; Spain.
\end{abstract}

Running title: Cigarette smoke, hypoxia and ventilation

Corresponding author:

Prof. Constancio Gonzalez.

Department of Biochemistry and

Molecular Biology and Physiology,

Universidad de Valladolid

47005 Valladolid, Spain.

Phone: +34 983423089

Fax: +34 983423588

e-mail: constanc@ibgm.uva.es 


\section{ABSTRACT}

Previously we have reported that association of cigarette smoke (CS) and chronic hypoxia $(\mathrm{CH})$ interact positively to physiopathologically remodel pulmonary circulation. In present study we have exposed guinea pigs to CS smoke (four cigarettes/day; 3 months; CS) and to chronic hypoxia (12\% $\mathrm{O}_{2}, 15$ days; $\left.\mathrm{CH}\right)$ alone or in combination ( $\mathrm{CSCH}$ animals) and evaluated airways remodeling and resistance assessed as Penh (enhance pause). We measured Penh while animals breathe air, $10 \% \mathrm{O}_{2}$ and $5 \% \mathrm{CO}_{2}$ and found that $\mathrm{CS}$ and $\mathrm{CH}$ animals have higher Penh than controls; Penh was even larger in $\mathrm{CSCH}$ animals. A rough parallelism between Penh and thickness of bronchiolar wall and muscular layer and Goblet cell number was noticed. We conclude that $\mathrm{CS}$ and $\mathrm{CH}$ association accelerates $\mathrm{CS}$-induced respiratory system damage, evidenced by augmented airway resistance, bronchial wall thickness and muscularization and Goblet cell number. Our findings would suggest that appearance of hypoxia would aggravate any preexisting pulmonary pathology by increasing airways resistance and reactivity.

Key Words: guinea pig, tobacco smoke, hypoxia, airways remodeling, Penh. 


\section{Introduction}

Animals, usually rodents, exposed to cigarette smoke (CS) are valuable models to study several types of lung and respiratory pathways pathology such as chronic obstructive pulmonary disease (COPD). Among those models, guinea pigs have proven to be very suitable (Wright and Churg, 1990, 2002a), as they tolerate prolonged smoke exposure without the very important and rapid weight loss encountered in other species (Finch et al., 1995; Chen et al., 2006). In an attempt to underscore the mechanisms involved in the genesis of the pathology found in COPD in humans most works have been centered on the study of lung parenchyma, (Wright and Churg, 2002a; Ardite et al., 2006; Church and Wright, 2007; Ferrer et al., 2009). Findings indicating that even if the pathology of the smoking lung in guinea pigs does not completely match that encountered in humans (in particular is not evident the centrilobular predominance of the smoke-induced human emphysema; Wright and Churg, 1990), the laboratory model reproduces the main morphological and functional traits of the human emphysema. Thus, after three months of smoking ten cigarettes a day it is evident an increase in the air-space size that affects alveoli and alveolar ducts, a decrease in the length of elastic fibers as well as increases in residual volume, functional residual capacity and total lung capacity. The severity of the alterations progresses with the duration of the smoke exposure (Wright and Churg, 1990) and with the extent of smoke exposure, as Ferrer et al. (2009) found that smoking seven cigarettes a day causes no enlargement of air spaces until six months of exposure.

Alterations in pulmonary vessel structure and function are highly prevalent in patients with COPD which commonly develop hypertension, which in turn represents one of the principal factors associated with reduced survival in COPD patients 
(Peinado et al., 2008). Importantly enough, although the reduction of capillary bed seems smaller in the experimental model than in humans (Yamato et al., 1997; Wright and Churg, 2002b), smoking guinea pig model has also been found to be adequate to reproduce pathological and functional alterations encountered in COPD patients. Thus, in two recent studies Ferrer et al. $(2009,2011)$ found a decrease in the lung expression of endothelial nitric oxide synthase after three months of CS exposure (seven cigarettes/day), preceding the appearance of lung emphysema; they also found that CS increased smooth muscle cell proliferation in small arteries leading to pulmonary arterial hypertension and causing right ventricle hypertrophy. Interestingly, association of CS (5 cigarettes/day, 3 months) and sustained hypoxia (last two weeks of CS), as it frequently occurs at some stage of evolution in COPD patients further exaggerated the alterations of pulmonary circulation leading to conclude that hypoxemia represents a critical step in the progression of pulmonary vascular impairment that amplifies the initial effects of CS.

Airways obstruction in the COPD patients has two different components, the volume-dependent airway obstruction due to a loss of the lung recoil and the airways narrowing component due to pathological alterations of the bronchial walls (Hogg et al., 2004). However, as pointed out by Wright and Churg (2002a) and Churg and Wright (2007) investigations on smoking animal models of COPD have paid little attention or even ignored (Churg et al., 2011) airways alterations. In smoking guinea pigs it has been found that after three months of ten cigarettes/day smoking there is an increase in the staining for neutral and acid mucins suggestive of Goblet cell hyperplasia/metaplasia (Wright et al., 1992; Wright and Churg, 2002a). In early works no changes were found in small airways wall thickness even after six and twelve months of CS exposure (Wright et al., 1992; Tron et al., 1987), but in more recent 
studies after six months of smoking seven cigarettes/day a thickening of wall of membranous bronchiole was seen (Churg et al., 2007). From a different perspective Joad and coworkers have reported in a series of studies that exposure of young guinea pigs to CS from weeks 1-6 of age causes airways C-fiber as well as brainstem neurons neurokinin-dependent sensitization setting the basis for exaggerated irritant induced bronchoconstriction and cough, as encountered in infants raised in homes with smokers (Mutoh et al., 1999; Joad et al., 2004; see also Kwong et al., 2001). The increased bronchoconstriction was evidenced by an increase in maximal Penh values (enhanced pause) after a citric acid aerosol application.

In present study we have used guinea pigs to study the effects of CS exposure on airways structure (bronchiolar wall thickness, Goblet cell number and bronchiolar muscle thickness) and airways resistance to flow assessed as enhanced pause (Penh). Since from the clinical point of view the interaction between cigarette smoke and hypoxia are very important as hypoxemia represents a critical step in the progression of pulmonary vascular impairment that amplifies the initial effects of CS. as in middle to advanced stages of the human COPD (Ferrer et al., 2011;see also Nizet et al., 2005; Le Jemtel et al. 2007), it would be desirable to know if the association of both factors, hypoxia and CS, accelerates the appearance or progression of the airways alterations. As a consequence we have followed the experimental paradigm used in our previous study (Ferrer et al.2011) to study the effects of CS and sustained hypoxia isolated and in association on airways parameters.

\section{Material and methods}

\subsection{Animals}


A group of 48 male Hartley guinea pigs (seven weeks of age) were purchased to Harlam Iberica and housed (3/cage) in an ad hoc room of the vivarium in a lightdark cycle of $12 \mathrm{~h}$ at a room temperature of $20-23{ }^{\circ} \mathrm{C}$. Animals were provided standard chow and water supplemented with vitamin C (Farma Bayer S.A., España; $1 \mathrm{~g} / \mathrm{l}) \mathrm{ad}$ libitum. After one week of adaption (i.e., at 8 weeks or 2 months of age), animals were randomly distributed in 2 groups of 24 animals and divided in subgroups (Figure 1). Twenty four animals were exposed to cigarette smoke for 3 months (12 weeks): 8 of them were maintained in normal atmosphere (smoking animals, CS) and 16 were exposed to a hypoxic atmosphere the last two smoking weeks (smoking hypoxic animals, $\mathrm{CSCH}$ ). The other group was similarly divided: 8 animals remained in normal atmosphere for the entire 12 weeks or 3 months (control animals, Control) and 16 were exposed to hypoxia for the last two weeks (chronic hypoxic animals, $\mathrm{CH}$ ). Body weight was measured weekly. Animal protocols were approved by the University of Valladolid Institutional Committee for Animal Care and Use following international laws and policies (Guide for the Care and Use of Laboratory Animals, National Institutes of Health, 85-23, 1985).

\subsection{Smoking protocol}

Animals were daily exposed to the smoke of 4 cigarettes (2R4F; Kentucky University Research; Lexington, KY, USA, 11 mg tar, 0.8 mg nicotine per cigarette), 5 days/week, using a nose-only inhalation system (Protowerx Design Inc; Langley, British Columbia, Canada). Control animals were equally sham-exposed.

\subsection{Exposure to chronic hypoxia}

Animals were introduced into glass chambers $(125 \mathrm{I} \times 50 \mathrm{~h} \times 50 \mathrm{w} \mathrm{cm} ; 8$ animals/chamber) continuously fluxed with a gas mixture $\left(12 \% \mathrm{O}_{2}\right.$ in $\mathrm{N}_{2} ; \mathrm{PO}_{2} \approx 85$ $\mathrm{mmHg}$; equivalent to $\approx 4300 \mathrm{~m}$ ) and kept for two weeks. Accumulation of $\mathrm{CO}_{2}$ was 
prevented by the continuous flow of the gas mixtures (31/min) and by a carbon dioxide absorbent (soda lime, Analema Vorquímica S.L., Spain). Guinea pigs remained in this atmosphere except for 30-40 min/day during routine maintenance and smoking session.

\subsection{Plethysmography}

The plethysmographic system allows recording pressure fluctuations within the chamber with a high gain differential transducer. Ideally, the frequency of pressure fluctuations would correspond to breathing frequency (fresp, breaths/min), but there are spurious fluctuations due to animal movements that were electronically rejected. The tidal volume $(\mathrm{VT}, \mathrm{ml}$ ) is provided by the software of the system from the integration of the inspiratory curve; the system was calibrated automatically by software after steady injection into the chamber of $5 \mathrm{ml}$ air. This integration was made at the recording conditions of temperature, pressure and water vapor saturation. Then, to express ventilatory volumes in BTPS conditions data were corrected for the body temperature of the guinea pig $\left(39^{\circ} \mathrm{C}\right.$; Schwenke et al., 2007) and water vapor saturation as well atmospheric pressure in Valladolid.

Ventilatory parameters were measured in conscious, freely moving guinea pigs by whole body plethysmography. The system (Emka Technologies, Paris, France with software IOX version 1.8.9.4) consisted of 5 litre methacrylate chambers continuously fluxed $(2 \mathrm{l} / \mathrm{min})$, with temperature inside of $22-24^{\circ} \mathrm{C}$. Animals were placed in the plethysmographic chamber flushed with compressed air for an initial period of around 30 min until they adapted to the chamber ambient and acquired a standard resting behaviour. Thereafter, we initiated the recording while flushing the plethysmographic chamber with 3 different gas mixtures: normoxia (fraction of inspired oxygen $\left(\mathrm{FI}_{\mathrm{O}_{2}}\right.$ of 0.21$)$, hypoxia $\left(\mathrm{FI}_{\mathrm{O}_{2}} 0.10\right.$ in $\left.\mathrm{N}_{2}\right)$ and hypercapnia 
(fraction of inspired carbon dioxide $\left(\mathrm{FI}_{\mathrm{CO}_{2}}\right.$ of 0.05 in air). Each recording period lasted $10 \mathrm{~min}$. At the outlet of one of the plethysmographic chambers we have an oximeter (Dräger, Sensor Oxydig, Lubbeck, Germany) to verify the $\mathrm{PO}_{2}$. Usually in 3-4 min the desired atmosphere is attained and therefore the analysis time is usually restricted to the last 6 min of exposure. Since in present study we were mostly interested in comparing respiratory parameters measured in identical conditions in all experimental groups, potential modifications in body temperature of the animals while breathing in the different atmospheres were not taken into account in those measurements. Parameters measured or computed include breathing frequency (fresp); tidal volume (VT); minute ventilation $\left(\dot{V}_{E}\right)$; inspiratory time $\left(\mathrm{T}_{\mathrm{I}}\right)$; expiratory time $\left(\mathrm{T}_{\mathrm{E}}\right)$; respiratory duty cycle ( $\mathrm{T}_{\mathrm{I}} / \mathrm{Tttot}$; mean inspiratory flow $\left(\mathrm{V}_{\mathrm{T}} / \mathrm{T}_{\mathrm{I}}\right)$; mean expiratory flow ( $\left.\mathrm{V}_{\mathrm{T}} / \mathrm{T}_{\mathrm{E}}\right)$; and enhanced pause (Penh). Penh was automatically computed by the software of the equipment and quantified according to the following formula:

$$
\text { Penh }=\left(\frac{P E F}{P I F}\right) \times\left[\left(\frac{T E}{\text { TE65 }}\right)-1\right]
$$

Where PIF = Peak Inspiratory Height in the plethysmographic recording; PEF = Peak Expiratory Height in the plethysmographic recording; $\mathrm{T}_{\mathrm{E}}=$ Expiratory Time; $\mathrm{TE}_{65}=$ Time to expire $65 \%$ of the "volume"; Pause $=\mathrm{TE}_{E} / \mathrm{TE}_{65}-1 ;$ Penh $=$ PEF/PIF $x$ Pause.

\subsection{Measurements of airway morphometry and Goblet cells}

Explanted lungs of 32 animals were inflated with $4 \%$ formaldehyde at a constant pressure of $25 \mathrm{~cm} \mathrm{H}_{2} \mathrm{O}$ during 24h, and then embedded in paraffin. Histological examination was performed in $4 \mu \mathrm{m}$ sections stained with hematoxylineosin (H\&E) and Alcian Blue for airway morphometry and Goblet cells quantification respectively. The external and the internal limits of the muscular layer were outlined 
and both total and lumen area were computed using an image analysis system (ImagePro Plus, Media Cybernetics, Inc Bethesda, MD). A total 230 sections of membranous bronchioles from the 32 animals (8 animals/group) were analyzed. External and internal areas were determined and bronchiolar wall thickness estimated as the difference between them. The area of the muscular layer of the bronchioles was estimated as the difference between the total and internal areas. The presence of Goblet cells was expressed as the number of cells per perimeter of bronchiolar epithelium (cells/mm). Additional methodological details can be found in Ferrer et al. (2009).

\subsection{Data presentation and statistics}

Data were evaluated using a Graph Pad Prism Software, version 4 (GraphPad Software Inc., San Diego, CA, USA) and were presented as mean \pm SEM. The significance of the differences between the means was calculated by One and TwoWay Analysis of Variance (ANOVA) for repeated measures (when applicable) with Newman-Keuls and Bonferroni multiple comparison tests, respectively. Potential interactions between $\mathrm{CS}$ and $\mathrm{CH}$ also were statistically assessed. Specific Statistical $P$ values of 0.05 or less were considered to represent significant differences.

\section{Results}

\subsection{Animal's general status. Evolution of body weight and hematocrit}

The general status of the smoking animals was normal in appearance and the motility and playing behaviour among cage mates was not obviously different from controls. Figure 2A shows the evolution of the body weight of animals. Weight gain in all groups ran parallel up to the 3 months of age. Thereafter, guinea pigs exposed to cigarette smoke (CS and CSCH groups) gain less weight than controls so that by the 
end of the 3 months exposure experimental animals weighed $19.5 \%$ less than control animals.

Hematocrit was measured at the end of the study and found to be increased in all experimental groups: CS (48 $\pm 2 ; \mathrm{p}<0.01), \mathrm{CH}(45 \pm 2 ; \mathrm{p}<0.05)$ and $\mathrm{CSCH}(51 \pm 1$; $\mathrm{p}<0.001)$ versus Control $(40 \pm 1)$. Hematocrit difference between $\mathrm{CH}$ and $\mathrm{CSCH}$ groups was statistically different $(p<0.001)$ and between CS and CSCH was marginally significant $(p=0.058)$. However, when statistical analysis for interaction was performed, it did not support a positive interaction indicating a simple additive effect between both stimuli ( $p>0.05)$.

\subsection{Ventilatory effects of acute hypoxia and hypercapnia in control} animals

Figure 3A shows sample plethysmographic recordings obtained in the same animal in the three different atmospheres, normoxia, hypoxia and hypercapnia. In Figure 3B we present mean values obtained in Control guinea pigs at all ages (2-5 months) in the three studied atmospheres: normoxia (air), hypoxia $\left(\begin{array}{lll}10 \% & \mathrm{O}_{2}\end{array}\right)$ and hypercapnia $\left(5 \% \mathrm{CO}_{2}\right.$ in air).

Normoxia (Room air, during $10 \mathrm{~min}$ ). Under this condition, the ventilatory pattern varied with age (Figure $3 \mathrm{~B}$, empty bars). fresp at a $\mathrm{FI}_{\mathrm{O}_{2}}$ of 0.21 did not change between 2 and 5 months of age (96 \pm 3 and $96 \pm 6$ breaths/min, respectively), while $\mathrm{V}_{\mathrm{T}}$ increased two fold in this period of time from $2.06 \pm 0.06 \mathrm{ml}$ at two months up to $4.15 \pm 0.14 \mathrm{ml}$ at five months $\left({ }^{\star \star *} \mathrm{p}<0.001\right.$ at all ages vs. two months). As a consequence, $\dot{V}_{E}$ also augmented with age, but the increase in $V_{T}$ and $\dot{V}_{E}$ run behind body weight gain so that $\dot{V}_{E} / \mathrm{Kg}$ of body weight decreased with age from 642 \pm 27 at two months down to $446 \pm 23 \mathrm{ml} / \mathrm{Kg}$ at five months $\left({ }^{\star \star \star} \mathrm{p}<0.001\right.$ at all ages vs. 2 months; Figure 3 empty bars). 
Hypoxia $\left(\mathrm{FI}_{\mathrm{O}_{2}}\right.$ of 0.10 , during $10 \mathrm{~min}$ ). Acute hypoxia did not alter the fresp, $\mathrm{V} \mathrm{T}$ or $\dot{V}_{E} / \mathrm{Kg}$ encountered in normoxic conditions at any age (Figure 3B, grey bars), indicating that guinea pigs do not hyperventilate in response to acute hypoxic hypoxia.

Hypercapnia $\left(\mathrm{FI}_{\mathrm{CO}_{2}}\right.$ of 0.05 in air, during $10 \mathrm{~min}$ ). fresp in hypercapnia was statistically identical at all ages. Hypercapnia caused a moderate but significant increase in the fresp as compared to normoxia at all ages but 5 months (+++ and +, $p<0.001$ and $p<0.05$, respectively; Figure $3 B$, black bars). $V_{T}$ in hypercapnic atmosphere increased with age being at 3,4 and 5 months statistically higher than at 2 months $\left({ }^{\star \star \star} p<0.001\right)$. At every age $V_{T}$ in hypercapnic atmosphere was nearly doubled than in normoxic conditions (+++ $p<0.001$; Figure 3). $\dot{V}_{E} / \mathrm{Kg}$ of body weight in hypercapnia declined with age being maximum at 2 months and minimum at 5 months ( ${ }^{\star \star \star} p<0.001$ at all ages vs. two months), but at any age it was nearly double that $\dot{V}_{E}$ encountered in normoxic atmosphere $(+++p<0.001)$. In other words, hypercapnia about doubled $\dot{V}_{E}$ at any studied age (Figure 3, black bars).

Table 1 shows $T_{I}, T_{E}, T_{I} / T_{\text {tot, }}, V_{T} / T_{I}$, and $V_{T} / T_{E}$ parameters in control animals at different ages. Results are comparable to those previously reported in young guinea pigs (Wiester et al., 1998).

\subsection{Penh}

Penh is a unit-less index which can be obtained in laboratory animals using whole body plethysmography. It is the unique indicator of airway responsiveness and airways resistance that can be obtained in conscious unrestrained animals and therefore is freed from the bias imposed by anesthesia or restraining stress. Figures 4A and 4B show, respectively, Penh values in Control and CS animals at all ages 
while breathing air, $\mathrm{FI}_{\mathrm{O}_{2}} 0.10$ or $\mathrm{FI}_{\mathrm{CO}_{2}} 0.05$. Notice first, that Penh values are nearly identical at all ages, secondly that Penh values are comparable in normoxia and hypoxia, and lastly that in hypercapnia Penh value was significantly higher, nearly double, than in the other two conditions $\left({ }^{\star \star \star} p<0.001\right)$ and was maximum at 4 months $(0.75 \pm 0.04)$ and minimum at 5 months $(0.53 \pm 0.03)$; in fact Penh was significantly higher at 4 months in comparison to all other ages $\left({ }^{\alpha \alpha} p<0.01\right)$.

In CS animals (Figure 4B) Penh increased in the three conditions with duration of the exposure to cigarette smoke, reaching maximum values after 2 months of exposure (4 months old; nearly $x 4$ control values; $+++p<0.001$ vs. Control of 4 months of age); at 3 months of exposure (5 months old) Penh remained high in comparison to age-matched controls $(+p<0.05 ;++p<0.01 ;+++p<0.001$ vs. 5 month old Control).

\subsection{Penh values and bronchiolar wall structure}

Figure 5 shows Penh values in 5 months old animals in Control, $\mathrm{CS}, \mathrm{CH}$ and $\mathrm{CSCH}$ groups, measured while breathing in air, $\mathrm{FI}_{\mathrm{O}_{2}} 0.10$ and $\mathrm{FI}_{\mathrm{CO}_{2}} 0.05$ atmospheres. Note first, that Penh values in the three experimental groups ( $\mathrm{CS}, \mathrm{CH}$ and $\mathrm{CSCH}$ ) were higher than in Control group in every condition (significance labeled by asterisks) and second, that Penh values were higher in $\mathrm{CSCH}$ than in $\mathrm{CS}$ and $\mathrm{CH}$ groups in the three atmospheres, differences reaching statistical significance while breathing air. The fact that in normal air atmosphere the differences in the values of Penh in the $\mathrm{CSCH}$ group vs. $\mathrm{CH}$ and $\mathrm{CS}$ groups reach statistical significance (significance labeled by alphas), would suggest a positive interaction between the two stressors (chronic hypoxia and cigarette smoke) to increase airways resistance, yet statistical analysis did not support it $(p>0.05)$. 
Top four images of Figure 6 show microphotographies of lung parenchyma evidencing a certain degree of alveolar walls thickening, as well as a higher level of inflammatory cell infiltration in sections from $\mathrm{CS}$ and $\mathrm{CH}$ animals. Both changes are more noticeable in the section of the $\mathrm{CSCH}$ where a clear neutrophilic-eosinophilic infiltration is evident. The four lower images are representative sections obtained from animals belonging to each of the four groups. It is apparent a thickening of the bronchiolar wall of $\mathrm{CH}$ and $\mathrm{CS}$, being particularly noticeable in $\mathrm{CSCH}$ group; the thickening of the bronchiolar muscle layer is also evident. A parallel increase in Goblet cell number is also increasingly noticeable from control to $\mathrm{CH}, \mathrm{CS}$, and $\mathrm{CSCH}$ sections (labelled by arrows).

The thickness of the bronchiolar wall is shown in Figure 7A. In $\mathrm{CS}$ and $\mathrm{CH}$ groups the area of the bronchiolar wall was larger but was not statistically different from controls. In $\mathrm{CSCH}$ group thickness of bronchiolar wall was nearly double than controls, being the differences highly significant $\left({ }^{\star *} \mathrm{p}<0.001\right)$; similarly it was different from $\mathrm{CS}$ and $\mathrm{CH}$ groups $\left({ }^{\alpha \alpha} \mathrm{p}<0.01\right)$. The same qualitative findings were attained if bronchiolar wall thickness is expresses as the ratio wall area/total bronchiole area. Also consistent with Penh values, are the thickness of bronchial muscle layer and number of Goblet cells/mm of bronchial epithelium which tend to be larger in CS and $\mathrm{CH}$ groups and were significantly larger in $\mathrm{CSCH}$ group $\left({ }^{\star \star} p<0.001 \mathrm{CSCH}\right.$ vs. Control; $+p<0.05$ and $++p<0.01 \mathrm{CS}$ and $\mathrm{CH}$ vs. $\mathrm{CSCH}$; interaction between tobacco and hypoxia was not statistically significant, $p>0.05$; Figure 7B)

\section{Discussion}

Our findings include: 1.) Cigarette smoke exposure produces a moderate timedependent decrease in the body weight; both cigarette smoke and chronic hypoxia 
synergistically increase the haematocrit; 2.) Age-dependent (2-5 months) ventilatory pattern of control guinea pigs includes a constant fresp, an increase in $\mathrm{V}_{\mathrm{T}}$ with age and an age-dependent decrease in $\dot{V}_{E} / \mathrm{Kg}$ of body weight; acute hypoxia does not alter the ventilatory pattern at any age, while acute hypercapnia causes a marked $\mathrm{V}_{\mathrm{T}}$ dependent increase in $\dot{V}_{E}$ at all ages; 3.) In control animals Penh values in 0.05 $\mathrm{Fl}_{\mathrm{CO}_{2}}$ atmosphere is about double than in air and $0.10 \mathrm{Fl}_{\mathrm{O}_{2}}$ atmospheres; 4.) In CS group Penh increases significantly as exposure time progresses whether it is measured in air, $0.10 \mathrm{Fl}_{\mathrm{O}_{2}}$, or $0.05 \mathrm{FI}_{\mathrm{CO}_{2}}$ atmospheres; 5.) Exposure to sustained hypoxia ( $\mathrm{CH}$ group) also increases Penh in the three conditions and, association of cigarette smoke and sustained hypoxia ( $\mathrm{CSCH}$ group) showed an additive effect to increase Penh in the three conditions; 6.) Thickness of the bronchiolar wall, thickness of the bronchial muscle layer, and number of Goblet cells in bronchi roughly paralleled to the increase in Penh values in all groups.

As previously reported (Ardite et al., 2006), prolonged smoke exposure curtails weight gain in guinea pigs. Coherent with findings in smokers humans (Yanbaeva et al., 2007), CS group showed an increase in the hematocrit, that probably results from a high carboxyhemoglobinemia (Wright and Churg, 1991). The increased hematocrit in $\mathrm{CH}$ group is also expected as an adaptive response to hypoxia mediated by HIF$1 \alpha$ (Semenza et al., 2006). In CSCH group both, hypoxic hypoxia and anaemic hypoxia (carboxyhemoglobinemia) would generate a higher compensatory-adaptive hematopoietic response.

The age-dependent variation in breathing pattern in the age window studied, 2-5 months, is characterized by a constant fresp and a progressive $\mathrm{V}_{\mathrm{T}}$ increase; yet, $\mathrm{V}_{\mathrm{T}}$ increased less than body weight causing an age dependent decrease in $\dot{\mathrm{V}}_{\mathrm{E}} / \mathrm{Kg}$. 
Absolute values of fresp, $V_{T}$ and $\dot{V}_{E}$ are comparable to those found by other authors (Yilmaz et al., 2005; Wiester et al., 1990, 2005). This age-dependent variation in ventilatory pattern is common in all mammals (Mortola, 2001) and parallels the mass specific metabolic rate. It should be noted, however, that maintenance of fresp and increase in $\mathrm{V}_{\mathrm{T}}$ tends to increase alveolar ventilation, and therefore, $\mathrm{O}_{2}$ uptake/Kg of body weight would decrease less than the measured $\dot{V}_{E} / \mathrm{Kg}$ of body weight. Consistent with most of the published studies (Blake and Banchero, 1985; Curran et al., 1995; Yilmaz et al., 2005; Schwenke et al., 2007; but see Fernandez et al., 2003), our data indicate a lack of hypoxia driven CB chemoreflex in adult guinea pigs. Admittedly, the intensity of the hypoxic test was moderate $\left(\mathrm{FI}_{\mathrm{O}_{2}} 0.10\right)$, but the same stimulus applied in the same conditions augmented fresp, $\mathrm{V}_{\mathrm{T}}$ and $\dot{\mathrm{V}}_{\mathrm{E}} / \mathrm{Kg}$ in rats by a factor of 1.6 (Agapito et al., 2009). Schwenke et al. (2007) in their experiments in anaesthetized guinea pigs used $8 \% \mathrm{O}_{2}$ and found that no recorded CSN responded to this hypoxic level and additionally that ventilation under $8 \% \mathrm{O}_{2}$ was not affected by CSN denervation. Contrary to the situation with hypoxia, in present experiments we observe that ventilatory response to hypercapnia is comparable to that obtained in the rat in comparable experimental conditions (Agapito et al., 2009) suggesting that in guinea pigs, as it is the case in the rat, $\mathrm{CO}_{2}$-triggered hyperventilation is mediated by CB and central chemoreceptors (Gonzalez et al., 1994), and implying that the lack of $\mathrm{CB}$ chemoreflex in guinea pigs refers exclusively to the hypoxia driven reflex. Consistent with our interpretation, Schwenke et al. (2007) observed in their anaesthetized guinea pigs that denervation of the CB in guinea pigs caused a ca. $28 \%$ decrease in the hyperventilation produced by $8 \% \mathrm{CO}_{2}$ breathing (Schwenke et al., 2007), a percentage which is comparable to that observed in most mammals, i.e., 
in guinea pigs, as in most mammals, the CB would contribute by around $30 \%$ to the $\mathrm{CO}_{2}$ triggered hyperventilation, with the remaining response being of central origin (Gonzalez et al. 1994). This in turn would indicate that the CB and its central projections to brainstem respiratory controllers are functional implying that the oxygen-sensing machinery (Gonzalez et al., 2004, 2007) could be absent in the CB of this species.

The experimental conditions used in present experiments to measure ventilatory response to hypoxia might not be ideal because ambient temperature is lower than neutral temperature in guinea pigs $\left[32^{\circ} \mathrm{C}\right.$ according to Hill (1959)]. In young adult guinea pigs comparable in weights to those used in our present experiments, Hill observed that at temperature below neutral, hypoxia $\left(10 \% \mathrm{O}_{2}\right.$ as in our experiments) causes a rapid hypometabolism assessed as a nearly $50 \%$ decrease in minute $\mathrm{O}_{2}$ consumption (this response with a higher or lower intensity also occurs in other mammals; Frappell et al., 1992; see also Mortolla and Frappell, 2000). In the rat, this decrease in oxygen consumption is mediated by mechanisms centred in the posterior hypothalamus (and probably additional brain areas) and produces a decrease in ventilation (Hinrichsen et al., 1998). Additionally, hypoxia as a result of the hypometabolism causes a slow and progressive decrease in body temperature (Hill, 1959; Mortolla and Frappell, 2000), which via CB chemoreceptors (see Zapata, 1997) would also tend to lessen any potential hypoxia-triggered CBmediated hyperventilation. In sum, these two factors, hypometabolism and hypothermia linked depression of ventilation, could be distorting our findings and masking any potential hypoxia-triggered CB-mediated hyperventilation. Although there are not specific data quantifying these effects in guinea pigs, it appears that in our experimental conditions they would be quantitatively very small by the following 
reasons: 1) the depression of ventilation by hypometabolism is variable from species to species (Frappell et al., 1992) and it is best evidenced at neutral or near neutral temperature in newborn animals with poorly developed CB chemoreflex (Mortola et al., 1989), 2) the hypothermic depression of CB function would be nil due to the short duration of the hypoxic exposure $(10 \mathrm{~min})$ and to the fact that the temperature of the plethysmographyc chamber was $22-24{ }^{\circ} \mathrm{C}$ (in Hill's experiments (1959) working at 20 ${ }^{\circ} \mathrm{C}$, body temperature dropped $\leq 0.5^{\circ} \mathrm{C}$ in $10 \mathrm{~min}$ ), and 3) the above-mentioned study of Schwenke et al. (2007) showing a lack of CB response to hypoxia carried out in adult guinea pigs was performed at constant body temperature of $39^{\circ} \mathrm{C}$ and the study by Curran et al. (1995) also showing the lack of a hypoxic ventilatory response in young 10-14 days old guinea pigs was performed at $33^{\circ} \mathrm{C}$ in the plethysmographic chamber, an ambient temperature that according to Hill (1959) would not change $\mathrm{O}_{2}$ consumption or body temperature. In sum, although guinea pigs as all mammals in hypoxia appear to have an increased ventilation to metabolism ratio (i.e., hyperventilate in relation to metabolic needs), it would appear that in our experimental conditions (temperature and duration of hypoxia) such hyperventilation would be minimal, but if any, it would be generated exclusively by a decrease in $\mathrm{O}_{2}$ consumption due to the unresponsiveness of their $C B$ to hypoxia. This abnormal response of guinea pigs, in comparison to other mammals, prevents us from reporting the impact of $\mathrm{CS}$ and $\mathrm{CSCH}$ on chemosensitivity

Literature on the value of Penh as a measure of airways resistance is divided, with some authors been attached to it (Bergren, 2001; Lomask, 2006) and some others neglecting its value (Flandre et al., 2003; for a recent discussion on the significance of Penh please see Vargas et al., 2010). Yet, in present study there are several findings that predicting an increase in airways resistance did indeed cause an 
increase in Penh values, and vice versa. 1) In Control group Penh values were double in $5 \% \mathrm{CO}_{2}$ than in air or $10 \% \mathrm{O}_{2}$. Taking into account that airways tone is reflexly controlled, being arterial and central chemoreceptors (among other) afferent arms of the reflex, and taking also into account that in guinea pig hypercapnia, but not hypoxia activates chemoreceptors, it should be expected, as indeed it is the case, that only hypercapnia increases Penh (Fitzgerald and Shirahata, 1997; PerezFontan et al., 1998; Canning 2006). In other words, $\mathrm{CO}_{2}$ that activates peripheral and central chemoreceptors increases Penh, while hypoxia that in guinea pigs does not activate chemoreceptors does not modify Penh. 2) CS animals have increased Penh values in all atmospheres. As mentioned in the introduction CS sensitizes C-fibres in airways by a neurokinin mediated mechanism leading to bronchial hyper reactivity (Joad et al., 2004), an in addition the increased number of Goblet cells would also contribute to generate hyperactive bronchiolar afferents, being well documented that mucous secretion activates airways afferents triggering reflex airways constriction (Canning 2006). 3) In CH Penh values are higher than in controls. This increase in Penh value would result from the thickening of the bronchial wall and bronchial muscle layer (probably mediated by HIF-1 $\alpha$; Semenza et al., 2006) and concurrent tendency of Goblet cells to increase. 4) Finally, the highest Penh value in $\mathrm{CSCH}$ animals is consistent with markedly increased Goblet cell number and thickening of bronchiolar wall and its muscular layer. In this context, we should emphasize the similarities of airways reactivity in guinea pigs and humans (Canning 2006). As a whole these findings indicate that tobacco smoke produces morphological and functional alterations in airways that would contribute to the obstruction encountered in COPD patients. The association of tobacco smoke and hypoxia thicken bronchial wall, increase Goblet cell number, and augment Penh values, more than each 
stressor individually, and therefore they could further contribute to airways obstruction. In addition it might be suggested that these structural alterations modify the pattern of stimulation of mechanoreceptors in airways (Yu, 2009) and thereby could alter breathing pattern.

In sum, exposure of guinea pigs to cigarette smoke during three months causes an increase in airways resistance. Co-exposure to cigarette smoke and chronic hypoxia causes a further increase in airways resistance. In addition, pulmonary hypertension and signs of vascular remodelling are exacerbated (Ferrer et al. 2011) on associating CS and hypoxia. These observations might have potentially relevant clinical correlates: it might be suggested that the appearance of hypoxemia in COPD patients would represent a sign that should be promptly corrected to avoid the triggering of feed-forward mechanisms that would endanger the survival of patients. In fact it is well recognized that hypoxemia in COPD patients augments the risk of right and left heart dysfunction or even failure; Nizet et al., 2005; Le Jemtel et al. 2007) as well as the frequency and severity of nocturnal desaturations and complicating lactacidosis (Toraldo et al., 2005). Even further, casual acute or sub acute hypoxic episodes (as for example sojourning at high altitude or a seasonal respiratory illness) might uncover unrecognized COPD patients or aggravate the clinical picture in patients with mild COPD. This could be so because well before the picture of emphysema is evident there is an increase in pulmonary circulation resistance-pulmonary hypertension that would be exaggerated by the hypoxic episodes due to pulmonary hypoxic vasoconstriction (Ferrer et al., 2011). Similarly, to the hyper reactivity of the bronchial wall caused by CS, which also appears before emphysema is apparent, it would add the high reflex bronco constrictor effect mediated by carotid body chemoreceptors and triggered by hypoxia (Gonzalez, et al., 
1994; Fitzgerald and Shirahata, 1997); the net result would be an exaggerated increase in airways resistance. Finally, our findings (additive effect between CS and hypoxia to increase Goblet cells, thickness of bronchiolar wall and muscle layer, and airways resistance) would provide a tentative explanation to the epidemiologically established observation that association of smoking (e.g., smoking mothers or smoke house) and hypoxia (frequent respiratory infections or sleep related apneas) constitutes a precipitating factor for the respiratory misregulation leading to loss of the arousal reaction to hypoxia and sudden infant dead (Kinney and Thach, 2009). Consistent with our interpretation Mutoh et al. (2000) have observed that the sensitization of the bronchopulmonary C-fibre endings is associated with a prolonged reflexively evoked expiratory apnea.

\section{Conflict of interest}

The authors declare no conflict of interest with the study or preparation of the manuscript.

\section{Acknowledgements.}

We want to thank $\mathrm{M}^{\mathrm{a}}$ de los Llanos Bravo and Elena Gonzalez for technical assistance. We also want to thank Milton J. Jensen, B. Sc. for correction manuscript's English style. The work was supported by the "Ministerio de Ciencia e Innovación of Spain", [grant number BFU2007-61848], by the "Instituto Carlos III", [grant number CIBER CB06/06/0050] and by "Fondo de Investigación de la Seguridad Social", [grant number FIS 04/1424].

\section{References}

Agapito MT, Sanz-Alfayate G, Gomez-Niño A, Gonzalez C, Obeso A (2009) General redox environment and carotid body chemoreceptor function. Am J Physiol Cell Physiol 296:C620-631. 
Ardite E, Peinado VI, Rabinovich RA, Fernández-Checa JC, Roca J, Barberà JA (2006) Systemic effects of cigarette smoke exposure in the guinea pig. Respir Med 100:1186-1194.

Bergren DR (2001) Chronic tobacco smoke exposure increases airway sensitivity to capsaicin in awake guinea pigs. J Appl Physiol 90:695-704.

Blake and Banchero (1985) Effects of cold and hypoxia on ventilation and oxygen consumption in awake guinea pigs. Respir Physiol 61:357-368.

Canning BJ (2006) Reflex regulation of airway smooth muscle tone. J Appl Physiol 101:971-985.

Chen H, Hansen MJ, Jones JE, Vlahos R, Bozinovski S, Anderson GP, Morris MJ (2006) Cigarette smoke exposure reprograms the hypothalamic neuropeptide $Y$ axis to promote weight loss. Am J Respir Crit Care Med. 173:1248-54.

Churg A, Sin DD, Wright JL. (2011) Everything Prevents Emphysema: Are Animal Models of Cigarette Smoke-Induced COPD Any Use?Am J Respir Cell Mol Biol. Jun 17. [Epub ahead of print].

Churg A, Wang R, Wang X, Onnervik PO, Thim K, Wright JL. (2007) Effect of an MMP-9/MMP-12 inhibitor on smoke-induced emphysema and airway remodelling in guinea pigs. Thorax. 62:706-13.

Churg A, Wright JL (2007) Animal models of cigarette smoke-induced chronic obstructive lung disease. Contrib Microbiol 14:113-125.

Curran AK, O'Halloran KD, Bradford A (1995) Effects of superior laryngeal nerve section on ventilation in neonatal guinea-pigs. Respir Physiol 101:23-29.

Fernández R, Arriagada I, Garrido AM, Larraín C, Zapata P (2003) Ventilatory chemosensory drive in cats, rats and guinea-pigs. Adv Exp Med Biol. 536:489-95. 
Ferrer E, Peinado VI, Castañeda J, Prieto-Lloret J, Olea E, González-Martín MC, Vega-Agapito MV, Díez M, Domínguez-Fandos D, Obeso A, González C, Barberà JA.(2011)Effects of cigarette smoke and hypoxia on the pulmonary circulation in the guinea pig. Eur Respir J. Feb 10. [Epub ahead of print]

Ferrer E, Peinado VI, Díez M, Carrasco JL, Musri MM, Martínez A, RodríguezRoisin R, Barberà JA. Effects of cigarette smoke on endothelial function of pulmonary arteries in the guinea pig. Respir Res. 2009 Aug 14;10:76.

Finch GL, Nikula KJ, Chen BT, Barr EB, Chang IY, Hobbs CH (1995) Effect of chronic cigarette smoke exposure on lung clearance of tracer particles inhaled by rats. Fundam Appl Toxicol. 24:76-85.

Fitzgerald RS, Shirahata M (1997) Systemic responses elicited by stimulating the carotid body: primary and secondary mechanisms. In: Gonzalez C, editor. The Carotid Body Chemoreceptors. Berlin: Springer-Verlag pp. 171-191.

Flandre TD, Leroy PL, Desmecht DJ (2003) Effect of somatic growth, strain, and sex on double-chamber plethysmographic respiratory function values in healthy mice. J Appl Physiol. 94:1129-36.

Frappell P, Lanthier C, Baudinette RV, Mortola JP (1992). Metabolism and ventilation in acute hypoxia: a comparative analysis in small mammalian species. Am J Physiol. 262:R1040-1046.

Gonzalez C, Agapito MT, Rocher A, Gonzalez-Martin MC, Vega-Agapito V, Gomez-Niño A, Rigual R, Castañeda J, Obeso A (2007) Chemoreception in the context of the general biology of ROS. Respir Physiol Neurobiol 157:30-44.

Gonzalez C, Almaraz L, Obeso A, Rigual R (1994) Carotid body chemoreceptors: From natural stimuli to sensory discharges. Physiol Rev 74: 829-898. 
Hill, JR (1959).The oxygen consumption of new-born and adult mammals. Its dependence on the oxygen tension in the inspired air and on the environmental temperature. J Physiol. 149:346-73.

Hinrichsen CF, Maskrey M, Mortola JP. (1998) Ventilatory and metabolic responses to cold and hypoxia in conscious rats with discrete hypothalamic lesions. Respir Physiol. 111:247-56.

Hogg JC, Chu F, Utokaparch S, Woods R, Elliott WM, Buzatu L, Cherniack RM, Rogers RM, Sciurba FC, Coxson HO, Paré PD. (2004). The nature of smallairway obstruction in chronic obstructive pulmonary disease. $\mathrm{N}$ Engl $\mathrm{J}$ Med. $350: 2645-53$.

Joad JP, Munch PA, Bric JM, Evans SJ, Pinkerton KE, Chen CY, Bonham AC (2004) Passive smoke effects on cough and airways in young guinea pigs: role of brainstem substance P. Am J Respir Crit Care Med 169:499-504.

Kinney HC, Thach BT. (2009) The sudden infant death syndrome. N Engl J Med. 361(8):795-805.

Le Jemtel TH, Padeletti M, Jelic S (2007) Diagnostic and therapeutic challenges in patients with coexistent chronic obstructive pulmonary disease and chronic heart failure. J Am Coll Cardiol 49:171-180.

Lomask M (2006) Further exploration of the Penh parameter. Exp Toxicol Pathol. 57 Suppl 2:13-20.

Mortola JP (2001) Respiratory Physiology of Newborn Mammals: A Comparative Perspective. The Johns Hopkins University Press, Baltimore, USA.

Mortola JP, Frappell PB. (2000) Ventilatory responses to changes in temperature in mammals and other vertebrates. Annu Rev Physiol. 62:847-74. 
Mortola JP, Rezzonico R, Lanthier C (1989). Ventilation and oxygen consumption during acute hypoxia in newborn mammals: a comparative analysis. Respir Physiol. 78:31-43.

Mutoh T, Bonham AC, Kott KS, Joad JP (1999) Chronic exposure to sidestream tobacco smoke augments lung C-fiber responsiveness in young guinea pigs. J Appl Physiol. 87:757-68.

Mutoh T, Joad JP, Bonham AC. (2000) Chronic passive cigarette smoke exposure augments bronchopulmonary C-fibre inputs to nucleus tractus solitarii neurones and reflex output in young guinea-pigs. J Physiol 523:223-33.

Nizet TA, van den Elshout FJ, Heijdra YF, van de Ven MJ, Mulder PG, Folgering HT (2005) Survival of chronic hypercapnic COPD patients is predicted by smoking habits, comorbidity, and hypoxemia. Chest 127:1904-1910.

Peinado VI, Pizarro S, Barberà JÁ (2008).Pulmonary vascular involvement in COPD. Chest. 134:808-14.

Pérez Fontán JJ, Kinloch LP, Donnelly DF (1998) Integration of bronchomotor and ventilatory responses to chemoreceptor stimulation in developing sheep. Respir Physiol 111:1-13.

Schwenke DO, Bolter CP, Cragg PA (2007) Are the carotid bodies of the guinea-pig functional? Comp Biochem Physiol A Mol Integr Physiol 146:180-188.

Seifert EL, Mortola JP. (2002) Circadian pattern of ventilation during acute and chronic hypercapnia in conscious adult rats. Am J Physiol Regul Integr Comp Physiol. 282:R244-51.

Semenza GL, Shimoda LA, Prabhakar NR (2006) Regulation of gene expression by HIF-1. Novartis Found Symp 272:2-8. 
Toraldo DM, Nicolardi G, De Nuccio F, Lorenzo R, Ambrosino N (2005) Pattern of variables describing desaturator COPD patients, as revealed by cluster analysis Chest 128:3828-3837.

Tron V, Wright JL, Harrison N, Wiggs B, Churg A. (1987). Cigarette smoke makes airway and early parenchymal asbestos-induced lung disease worse in the guinea pig. Am Rev Respir Dis. 136:271-5.

Vargas MH, Sommer B, Bazán-Perkins B, Montaño LM. (2010).Airway responsiveness measured by barometric plethysmography in guinea pigs. Vet Res Commun. 2010 Oct;34(7):589-96.

Wiester MJ, Costa DL, Tepper JS, Winsett DW, Slade R (2005) Agonistmediated airway challenge: cardiopulmonary interactions modulate gas exchange and recovery. Respir Physiol Neurobiol 145:183-199.

Wiester MJ, Tepper JS, King ME, Ménache MG, Costa DL (1988) Comparative study of ozone (O3) uptake in three strains of rats and in the guinea pig. Toxicol Appl Pharmacol 96:140-146.

Wright JL, Churg A (1990) Cigarette smoke causes physiologic and morphologic changes of emphysema in the guinea pig. Am Rev Respir Dis 142:14221428.

Wright JL, Churg A. (1991) Effect of long-term cigarette smoke exposure on pulmonary vascular structure and function in the guinea pig. Exp Lung Res 17:9971009.

Wright JL, Churg A (2002a) Animal models of cigarette smoke-induced COPD. Chest 122:301S-306S.

Wright JL, Churg A. (2002b) A model of tobacco smoke-induced airflow obstruction in the guinea pig. Chest. 2002b May;121(5 Suppl):188S-191S. 
Wright JL, Ngai T, Churg A. (1992). Effect of long-term exposure to cigarette smoke on the small airways of the guinea pig. Exp Lung Res. 18:105-14.

Wright JL, Postma DS, Kerstjens HA, Timens W, Whittaker P, Churg A (2007) Airway remodeling in the smoke exposed guinea pig model. Inhal Toxicol 19:915923.

Yamato H, Sun JP, Churg A, Wright JL (1997) Guinea pig pulmonary hypertension caused by cigarette smoke cannot be explained by capillary bed destruction. J Appl Physiol 82:1644-53.

Yanbaeva DG, Dentener MA, Creutzberg EC, Wesseling G, Wouters EF (2007) Systemic effects of smoking. Chest 131:1557-1566.

Yilmaz C, Hogg DC, Ravikumar P, Hsia CC (2005) Ventilatory acclimatization in awake guinea pigs raised at high altitude. Respir Physiol Neurobiol 145:235-242.

Yu J. (2009) Airway receptors and their reflex function--invited article. Adv Exp Med Biol. 648:411-20.

Zapata P (1997). Chemosensory activity in the carotid nerve: Effects of physiological variables. In: Gonzalez C, editor. The Carotid Body Chemoreceptors. Berlin: Springer-Verlag pp. 97-117. 


\section{Figure legends}

Figure 1. Experimental groups and protocols. The schema shows, groups of guinea pigs used in present study (rectangular boxes), including duration of exposure to tobacco smoke in $\mathrm{CS}$ group, exposure to chronic hypoxia in $\mathrm{CH}$ group and coapplication of both stressors in $\mathrm{CSCH}$ group. In every case ventilatory parameters were measured monthly as indicated by dots in each box. In analyzing the data and figure drawing in the entire study, data obtained in control group and in $\mathrm{CH}$ group up to 4 months were combined. An identical combination was made with data of CS group and $\mathrm{CSCH}$ group up to 4 months.

Figure 2. Body weight and hematocrit values in Control, cigarette smoke exposed (CS), chronic hypoxia exposed $(\mathrm{CH})$ and both cigarette smoke and hypoxia exposed $(\mathrm{CSCH})$ guinea pigs. A. Body weight evolution during the experiments (3 months) in the four groups of guinea pigs (from 2 to 5 months of age). $++p<0.01$ and $+++p<0.001 \mathrm{CS}$ and $\mathrm{CSCH}$ vs. Control and $\mathrm{CH}$ (Two way ANOVA with age and treatment as independent factors). B. Hematocrit in the four groups of animals as label in the figure. Data are means \pm SEM. ${ }^{*} p<0.05 ;{ }^{* \star} p<0.01 ;{ }^{* \star} p<0.001$ every group vs. Control; $+++p<0.001 \mathrm{CSCH}$ vs. $\mathrm{CH}$ (one way ANOVA). In every case, sample sizes as depicted in Figure 1.

Figure 3. Age-dependent breathing pattern in control guinea pigs while breathing in-air, $\mathrm{FI}_{\mathrm{O}_{2}} 0.10$ and $\mathrm{FI}_{\mathrm{CO}_{2}} 0.05$ atmospheres. A. Sample rough plethysmographic recordings. B. Top, breathing frequency (fresp). $+p<0.05$ $+++p<0.001, \mathrm{Fl}_{\mathrm{CO}_{2}} 0.05$ vs. air. Middle, tidal volume $\left(\mathrm{V}_{\mathrm{T}}\right)^{* \star *} \mathrm{p}<0.001$ at 3,4 and 5 months vs. 2 months $+++p<0.0015 \% \mathrm{CO} 2$ vs. air. Bottom, minute ventilation/Kg of 
body weight ${ }^{* *} p<0.001{ }^{*} p<0.01$ at 3,4 and 5 months vs. 2 months $+++p<0.001$ $5 \% \mathrm{CO} 2$ vs. air. Data are means \pm SEM (statistical significances were obtained using a two-way ANOVA for repeated measures, with age and breathing atmospheres as independent factors). In every case, sample sizes as depicted in Figure 1.

Figure 4. Enhanced pause (Penh) values in Control and cigarette smoke exposed guinea pigs while breathing air, $\mathrm{Fl}_{\mathrm{O}_{2}} 0.10$, and $\mathrm{FI}_{\mathrm{CO}_{2}}$ 0.05. .A shows data for control animals of different ages. ${ }^{* *} p<0.001$ vs. air breathing. ${ }^{\alpha \alpha} p<0.01$ hypercapnic breathing at 4 months vs. all other ages. B shows data for animals exposed to cigarette smoke during different periods of time. Crosses label statistical differences from age matched controls (statistical significances were obtained using a two-way ANOVA for repeated measures, with age and breathing atmospheres as independent factors when comparing within group of smoking animals; when comparing smoking animals with age-matched controls the independent factors were breathing atmospheres and treatment). In every case, sample sizes as depicted in Figure 1.

Figure 5. Penh values in the three experimental groups ( $\mathrm{CS}, \mathrm{CH}$ and $\mathrm{CSCH})$ at 5 months of age. In all experimental groups Penh values were higher than in Control in the three atmospheres $\left({ }^{*} p<0.05 ; p<0.01\right.$ and $p<0.001$ vs. Control and correspondent atmosphere). ${ }^{\alpha} p<0.05$ and ${ }^{\alpha \alpha} p<0.01$ air in $\mathrm{CSCH}$ vs. $\mathrm{CS}$ and $\mathrm{CH}$ groups, respectively (Two-way ANOVA with treatment and atmosphere as independent factors). In every case, sample sizes as depicted in Figure 1.

Figure 6. Parenchymal lung tissue and small bronchi photomicrographs. The top four images are sections of lung parenchyma obtained from control, smoking (CS), chronic hypoxic $(\mathrm{CH})$ and hypoxic smoking $(\mathrm{CSCH})$ animals. Four lower sections corresponding to same experimental groups contain small caliber bronchi to evidence the thickness of bronchial wall and the density of Goblet cells (arrows). 
Figure 7. A. Bronchiolar wall area determined as the difference between total and internal areas of the bronchioles. ${ }^{* *} p<0.001$ vs. control; ${ }^{\alpha \alpha} p<0.01$ vs. $\mathrm{CS}$ and $\mathrm{CH}$ (one way ANOVA). B. Goblet cell number and thickness of bronchial muscular layer in the four experimental groups. Statistical significance: ${ }^{* \star} \mathrm{p}<0.001 \mathrm{CSCH}$ vs. Control; Crosses differences among $\mathrm{CS}$ and $\mathrm{CH}$ vs. $\mathrm{CSCH}$ groups as labeled (independent one way ANOVA for each parameter). In every case, sample sizes as depicted in Figure 1. 


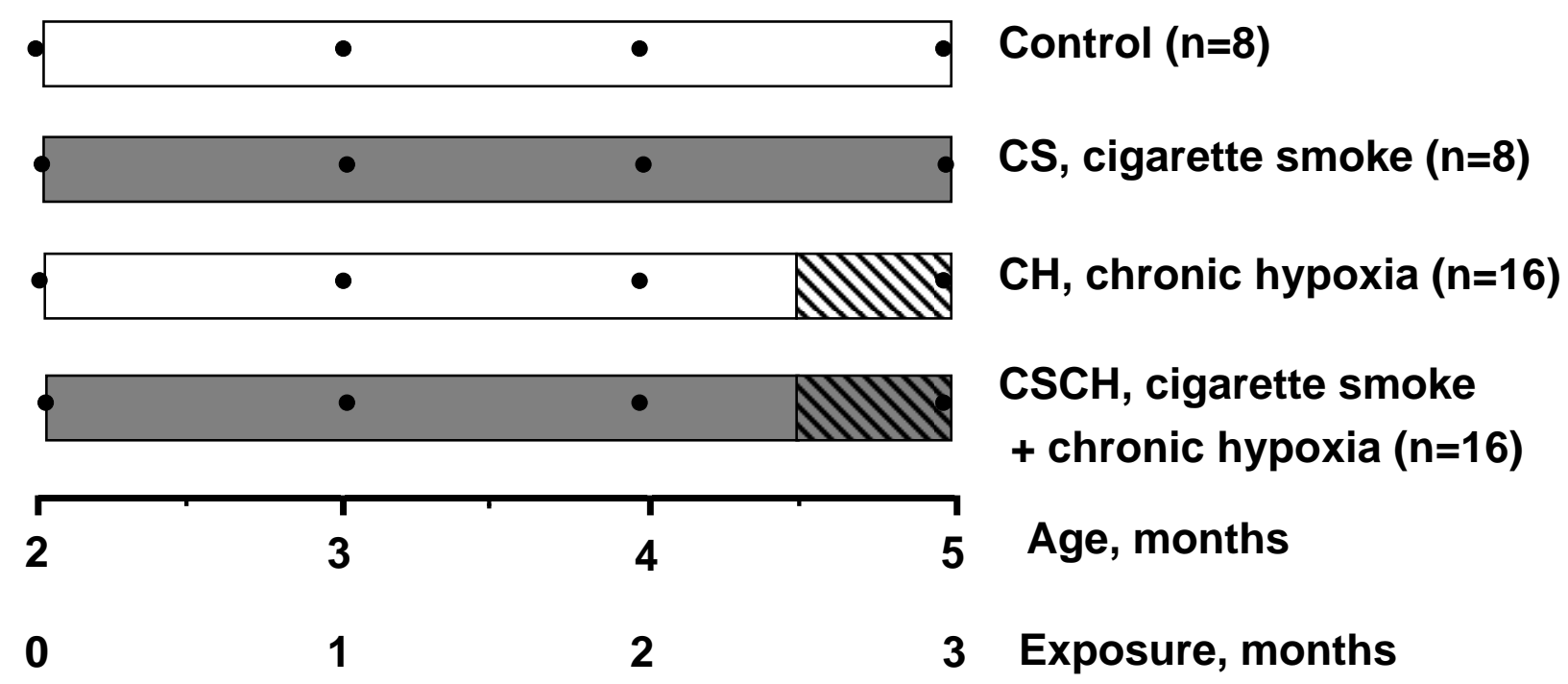




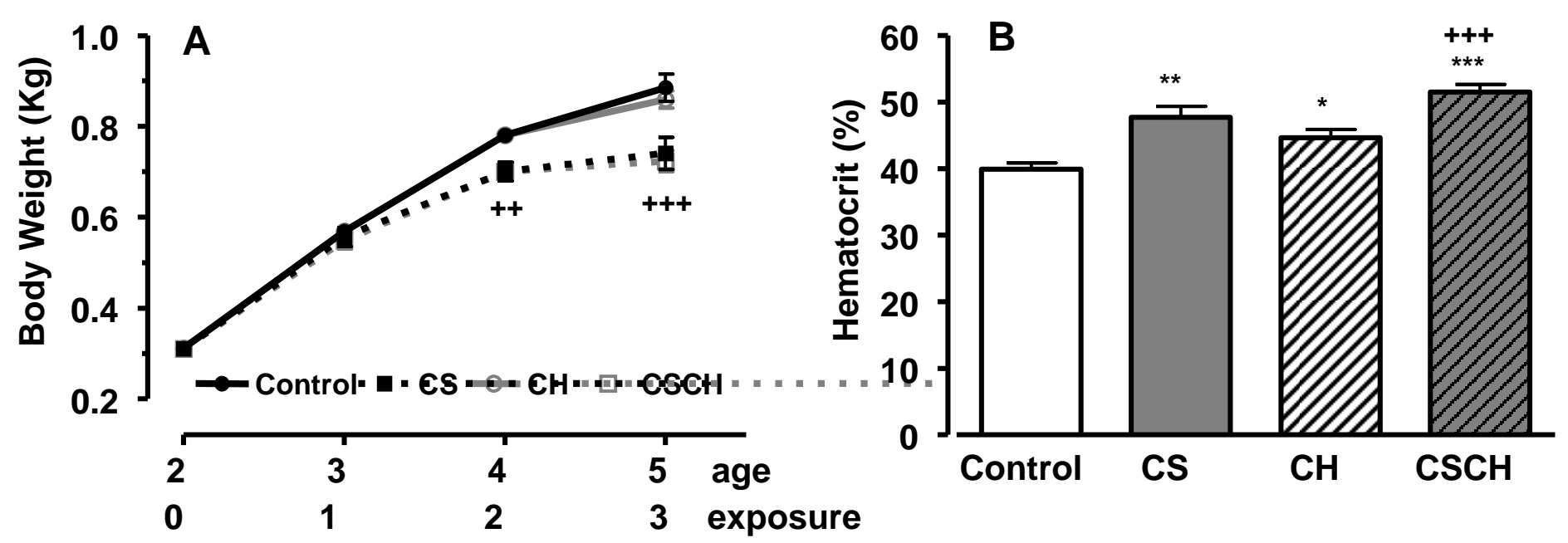




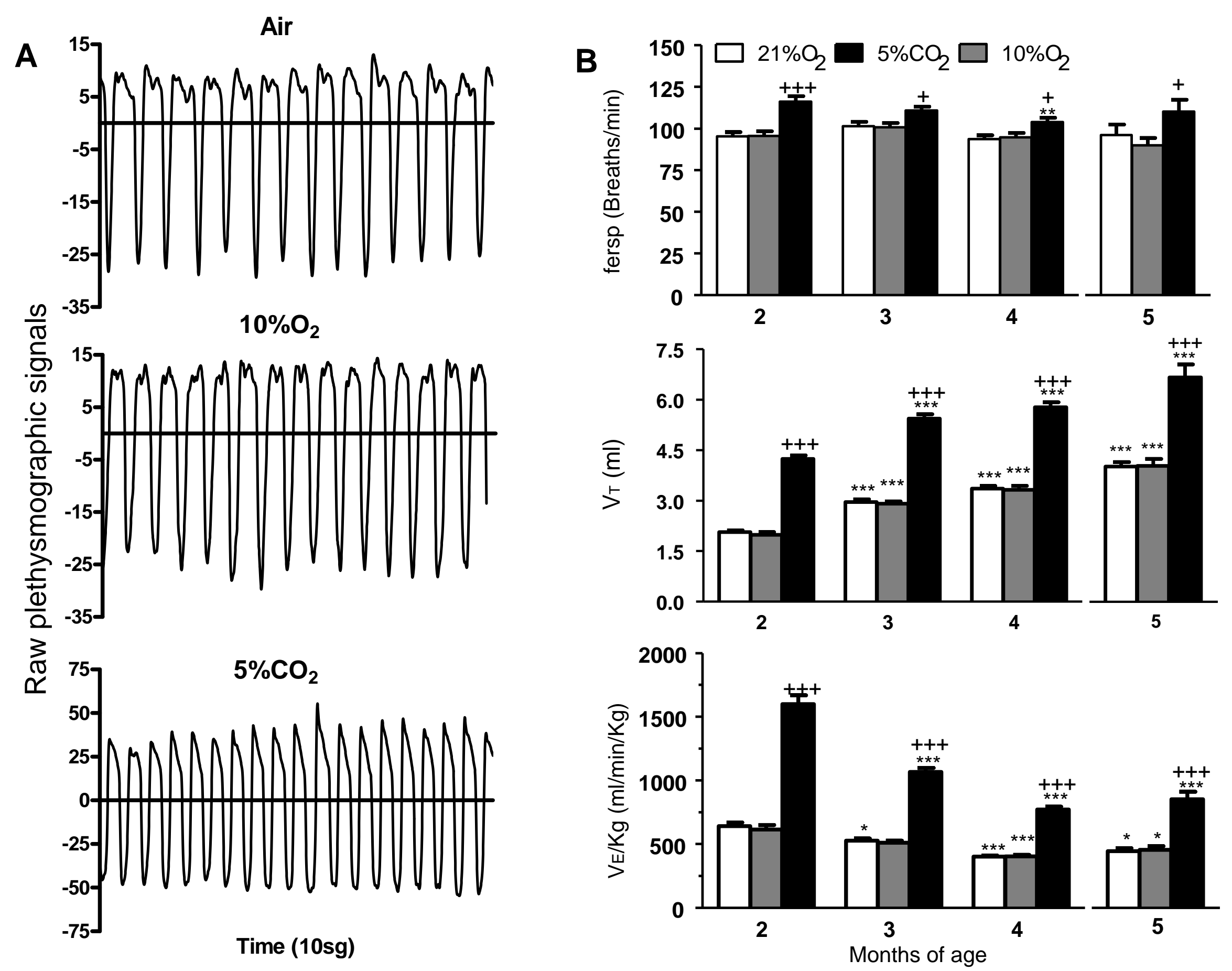



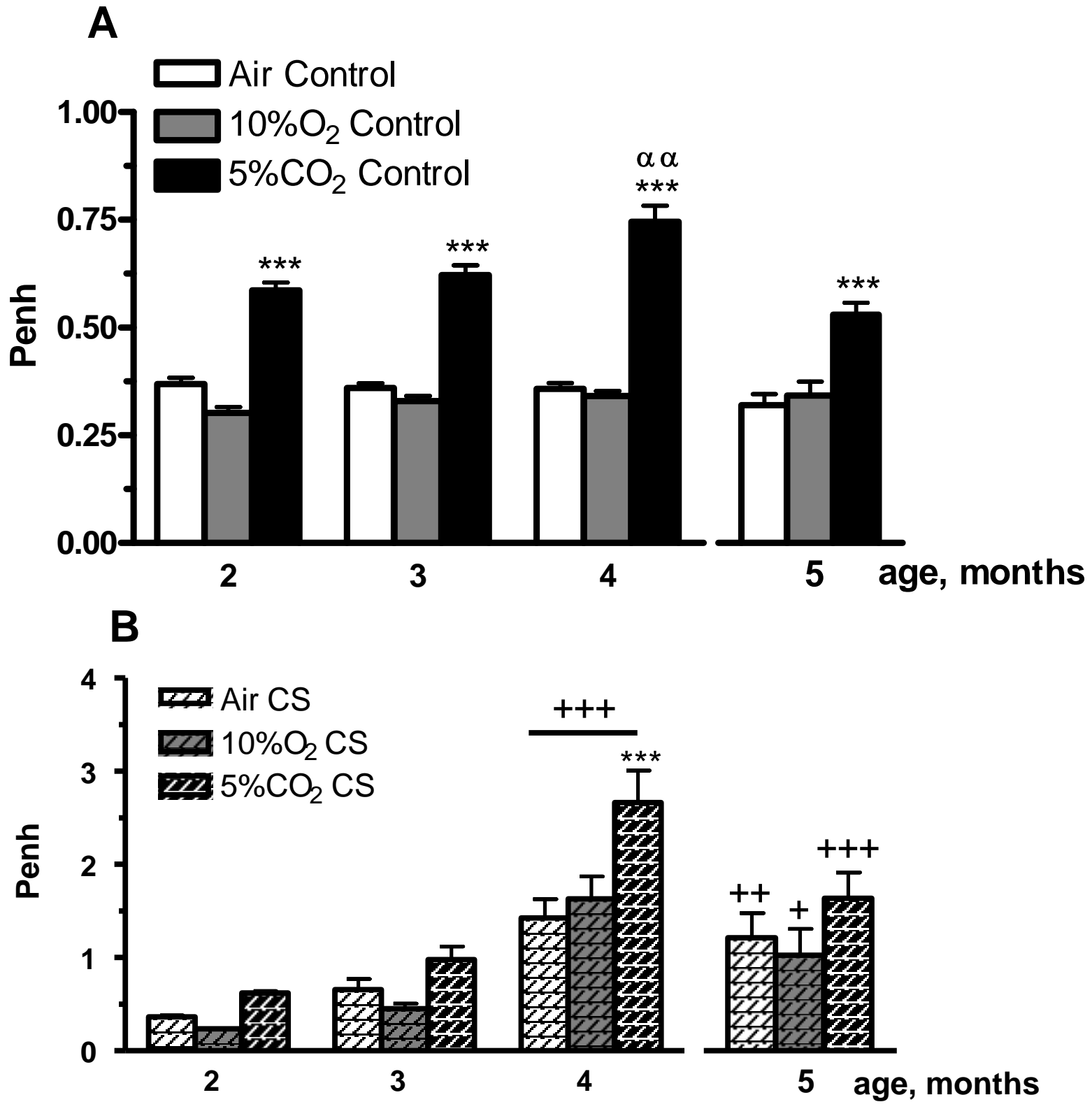


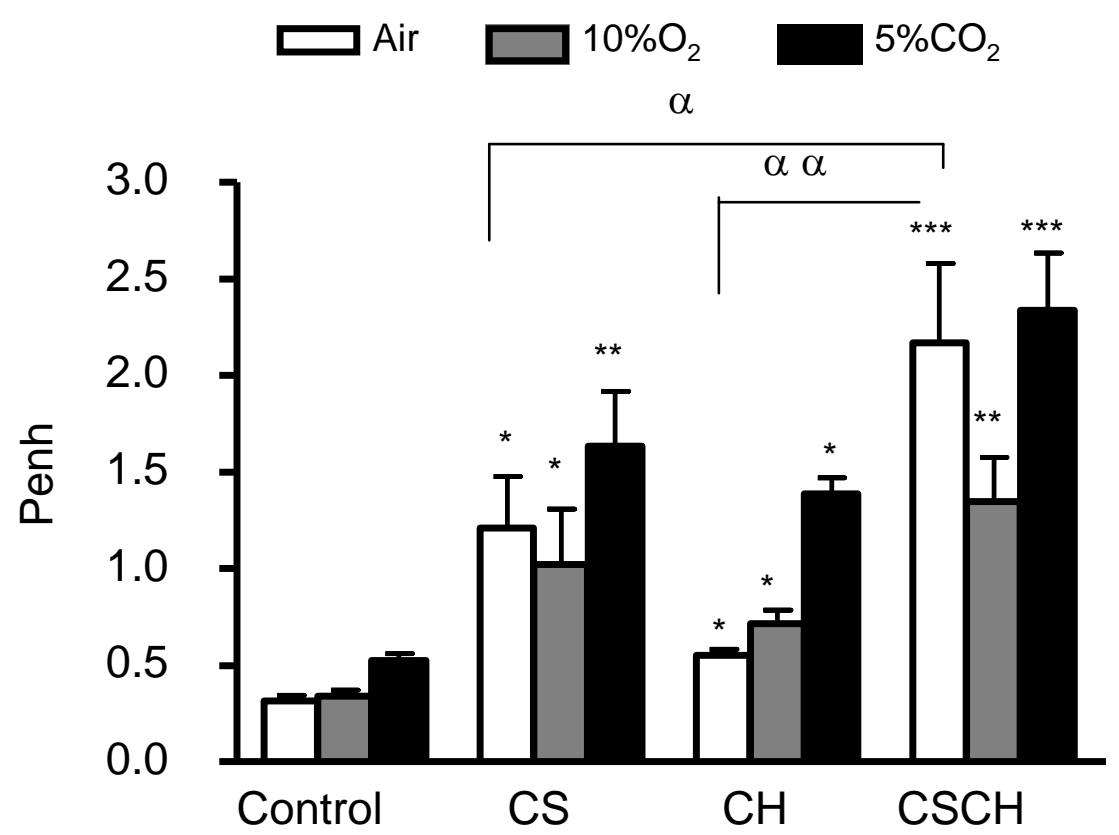



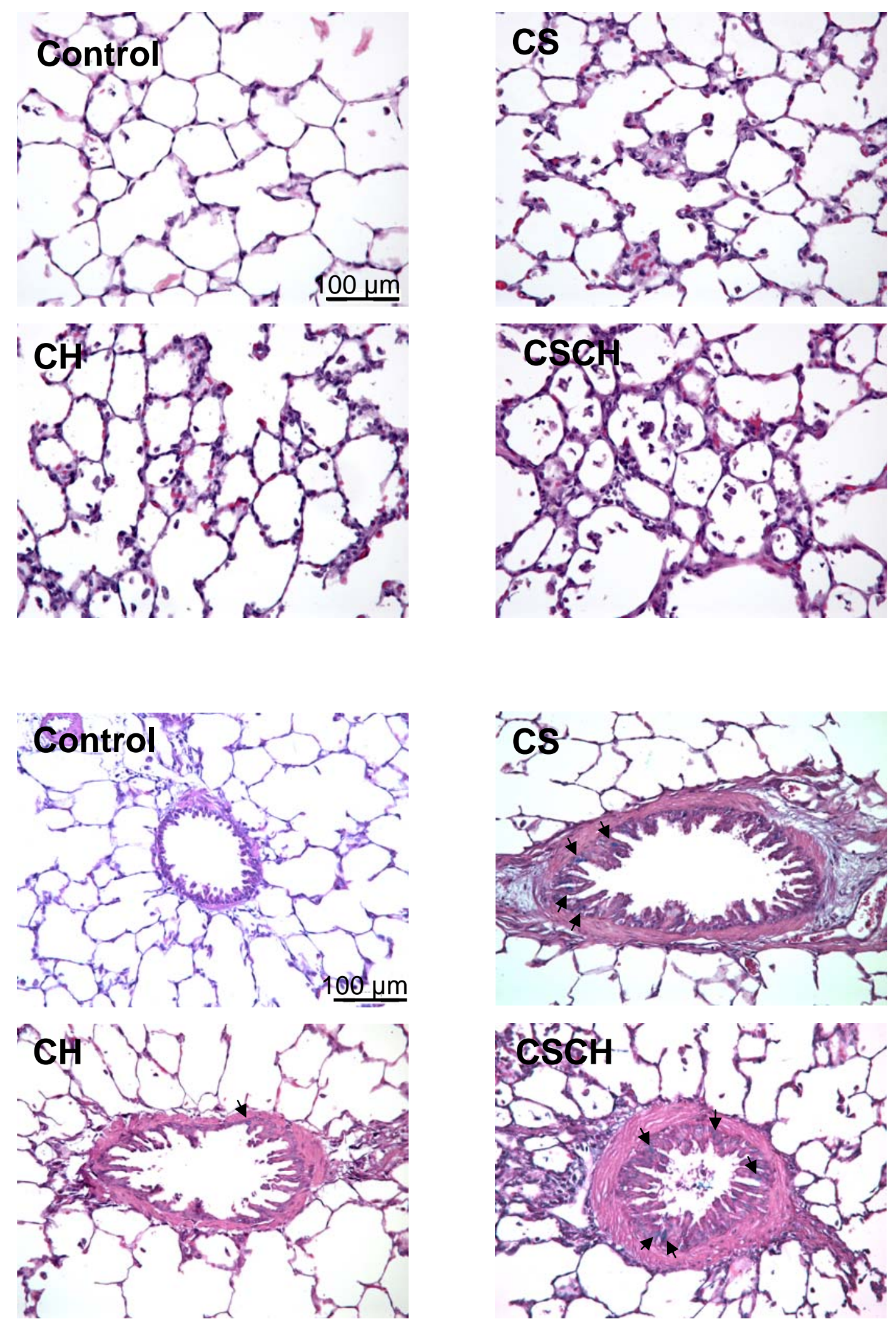
A

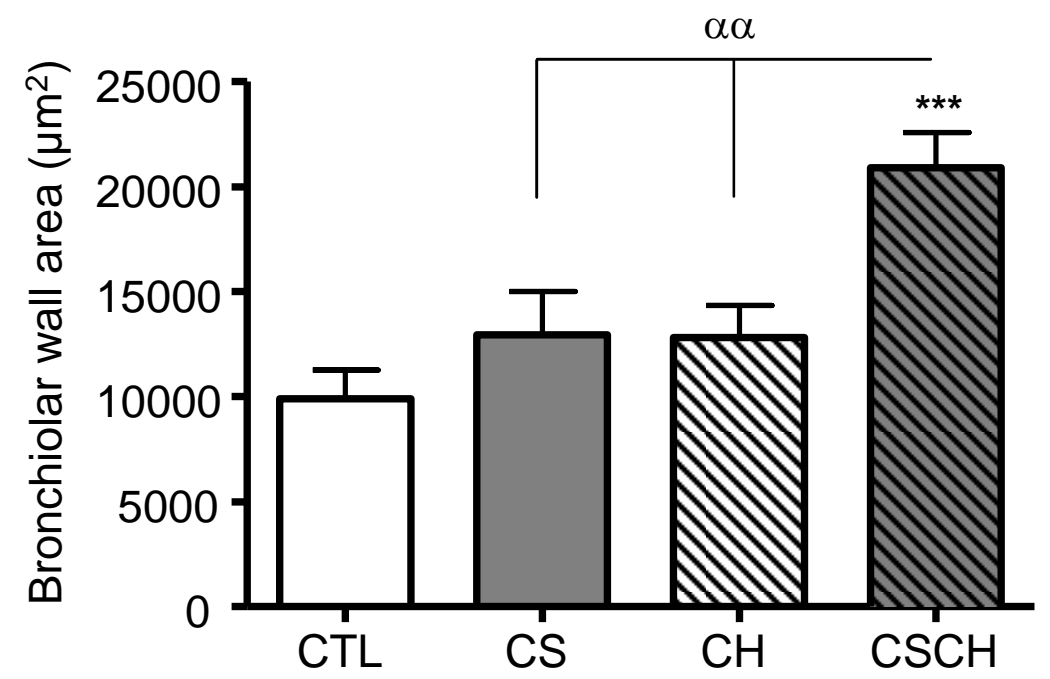

B

Muscular Thickness

Goblet cells

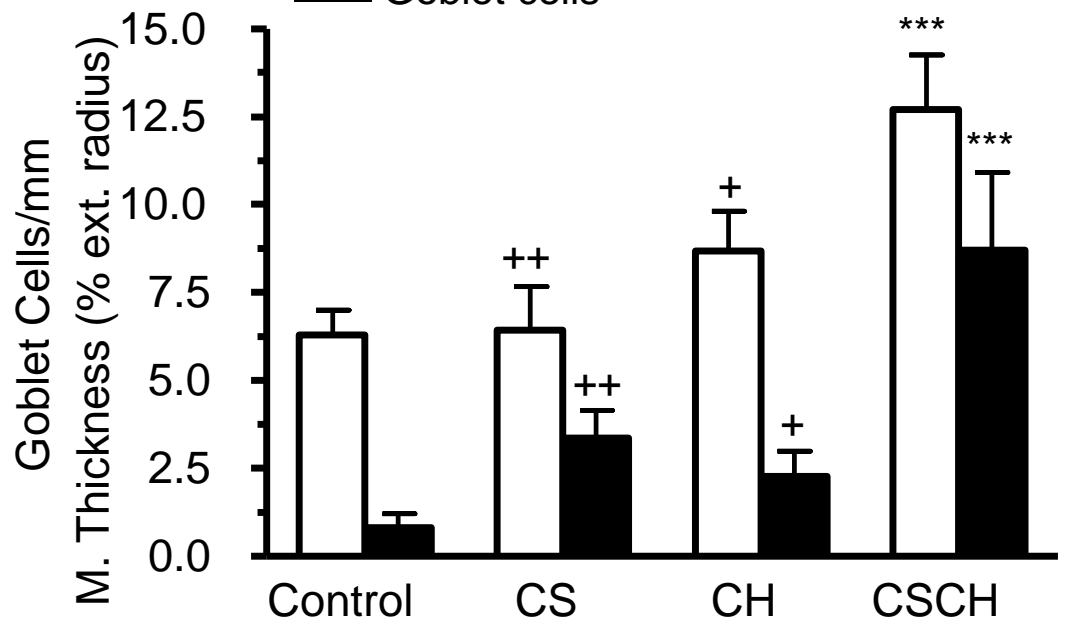


Table 1. Ventilatory times and flows in control guinea pigs

\begin{tabular}{|c|c|c|c|c|c|}
\hline Age months) & $\mathrm{T}_{\mathrm{I}}(\mathrm{ms})$ & $\mathrm{T}_{\mathrm{E}}(\mathrm{ms})$ & $\mathrm{T}_{\mathrm{I}} / \mathrm{T}_{\mathrm{Tot}}(\%)$ & $\begin{array}{c}\mathrm{V}_{\mathrm{T}} / \mathrm{T}_{\mathrm{I}} \\
(\mathrm{ml} / \mathrm{s})\end{array}$ & $\mathrm{V}_{\mathrm{T}} / \mathrm{T}_{\mathrm{E}}(\mathrm{ml} / \mathrm{s})$ \\
\hline 2 & $262.9 \pm 7.3$ & $397.3 \pm 12.1$ & 39.8 & 7.83 & 5.18 \\
\hline 3 & $244.9 \pm 7.0$ & $372.3 \pm 10.3$ & 39.5 & 12.08 & 7.95 \\
\hline 4 & $265.7 \pm 7.0$ & $402.1 \pm 9.9$ & 39.7 & 12.60 & 8.33 \\
\hline 5 & $256.6 \pm 14.9$ & $409.8 \pm 25.4$ & 38.5 & 16.17 & 10.12 \\
\hline
\end{tabular}

Inspiratory time $\left(\mathrm{T}_{\mathrm{I}}\right)$, expiratory time $\left(\mathrm{T}_{\mathrm{E}}\right), \%$ time of the respiratory cycle occupied by inspiration $\left(\mathrm{T}_{\mathrm{I}} / \mathrm{T}_{\text {tot }}(\%)\right.$, inspiratory flow $\left(\mathrm{V}_{\mathrm{T}} / \mathrm{T}_{\mathrm{I}}\right)$ and expiratory flow $\left(\mathrm{V}_{\mathrm{T}} / \mathrm{T}_{\mathrm{E}}\right)$. 